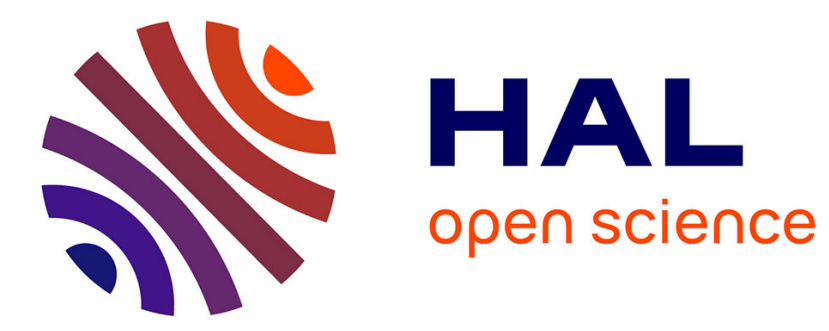

\title{
The melt-growth and characterization of cadmium telluride
}

\author{
J.B. Mullin, B.W. Straughan
}

\section{To cite this version:}

J.B. Mullin, B.W. Straughan. The melt-growth and characterization of cadmium telluride. Revue de Physique Appliquée, 1977, 12 (2), pp.105-115. 10.1051/rphysap:01977001202010500 . jpa-00244128

\section{HAL Id: jpa-00244128 https://hal.science/jpa-00244128}

Submitted on 1 Jan 1977

HAL is a multi-disciplinary open access archive for the deposit and dissemination of scientific research documents, whether they are published or not. The documents may come from teaching and research institutions in France or abroad, or from public or private research centers.
L'archive ouverte pluridisciplinaire HAL, est destinée au dépôt et à la diffusion de documents scientifiques de niveau recherche, publiés ou non, émanant des établissements d'enseignement et de recherche français ou étrangers, des laboratoires publics ou privés. 
Section I. 1 : Crystal Growth.

\title{
THE MELT-GROWTH AND CHARACTERIZATION OF CADMIUM TELLURIDE
}

\author{
J. B. MULLIN and B. W. STRAUGHAN
}

Royal Signals \& Radar Establishment, Malvern, UK

\begin{abstract}
Résumé. - Dans cet exposé on passe en revue les différentes méthodes de croissance de tellurure de cadmium à partir de bains fondus. On s'intéressera plus particulièrement aux techniques de contrôle de la pression de dissociation. Les avantages potentiels d'une compensation de pressions sont considérés simultanément aux premiers résultats obtenus par une croissance sous encapsulation liquide. La caractérisation des cristaux tirés sous encapsulation liquide nécessite une étude des principaux défauts physiques, des impuretés et des associations impuretés-défauts. On s'intéressera à l'origine de ces perturbations et on proposera des solutions en vue de leur contrôle, voire leur élimination.
\end{abstract}

\begin{abstract}
Developments in the melt-growth of CdTe are reviewed particularly with respect to techniques for controlling the dissociation pressure. The potential merits of Pressure Balancing are considered together with the results of a preliminary LEC growth investigation. The characterization of the LEC crystals involves a survey of the main defects-low angle grain boundaries twins, dislocations, precipitates, impurities and impurity defects-together with a discussion on their origin, and experience and suggestions for their elimination or control.
\end{abstract}

1. Introduction. - In reviewing developments in the melt-growth of CdTe the main considerations will assess the field of stoichiometric or near-stoichiometric growth although some pertinent aspects of solution growth will be considered. The main emphasis will be on the LEC-growth of CdTe and the characterization of the pulled crystals.

The growth of any large single crystal semiconductor with predetermined properties is an ultimate goal for most crystal growers. The slow painstaking struggle against capricious odds is like following a mirage. Cadmium telluride is no exception to this pattern, and, whilst impressive strides have been made in improvements in the quality and perfection of crystals in the last few years the ultimate goal is not yet within the grasp of the crystal grower. One uncontrollable obstacle is unfortunately the device man who constantly moves the goal.

A good cross-sectional view of the state of development of the melt-growth of CdTe was presented at the last symposium by various authors including Strauss [1], Kyle [2], Triboulet [3] and Vandekerkof [4]. The splendid review by Strauss [1] analysed the closed tube technologies, both horizontal and vertical with and without a $\mathrm{Cd}$ reservoir, for the melt-growth of $\mathrm{CdTe}$. A detailed re-examination of these procedures is not therefore necessary here. The main physicochemical aspects of CdTe will however be considered in order to set in perspective the problems of growing $\mathrm{CdTe}$ and also to provide a framework for discussing LEC growth and for considering the possibility of an alternative technique, Pressure Balancing [5]. This latter dormant technique has conceptually appealing characteristics for the growth of CdTe.

2. The pressure problem. - The melt-growth of CdTe is normally carried out in a regime where solid CdTe separates from a homogeneous liquid phase of $\mathrm{Cd}$ plus $\mathrm{Te}$ which is in substantial equilibrium with a mixture of $\mathrm{Cd}$ and $\mathrm{Te}$ vapours. According to the phase rule the system is univariant and one parameter such as the temperature (an independent parameter) completely determines the system. The significance of this for the growth of CdTe can be seen from the phase relationship that was reported by Strauss [1] and is reproduced here as figure 1. Two dependent parameters, the $\mathrm{Cd}$ and $\mathrm{Te}$ partial pressures, are plotted on the same graph as a function of the reciprocal temperature. At the maximum melting point the partial pressures of $\mathrm{Cd}$ and $\mathrm{Te}$ are respectively $\sim 0.7 \mathrm{~atm}$ and $\sim 5 \times 10^{-3} \mathrm{~atm}$. Thus to achieve growth under near equilibrium conditions it would be necessary either $a$ ) to maintain a $\mathrm{Cd}$ vapour pressure over the melt of $\sim 0.7 \mathrm{~atm}$ by using a Cd reservoir at $\sim 728^{\circ} \mathrm{C}$ and also to ensure that the vapour did not contact any surface having a temperature less than $\sim 728^{\circ} \mathrm{C}$ or b) to use a completely sealed system where the containing wall temperatures were not less than $\sim 728^{\circ} \mathrm{C}$ ie using so-called hot-wall technology. There is a minimum constraint for the Te pressure which would be satisfied by the $\mathrm{Cd}$ constraint noted above. Working at significantly higher or lower pressures of $\mathrm{Cd}$ constitute 


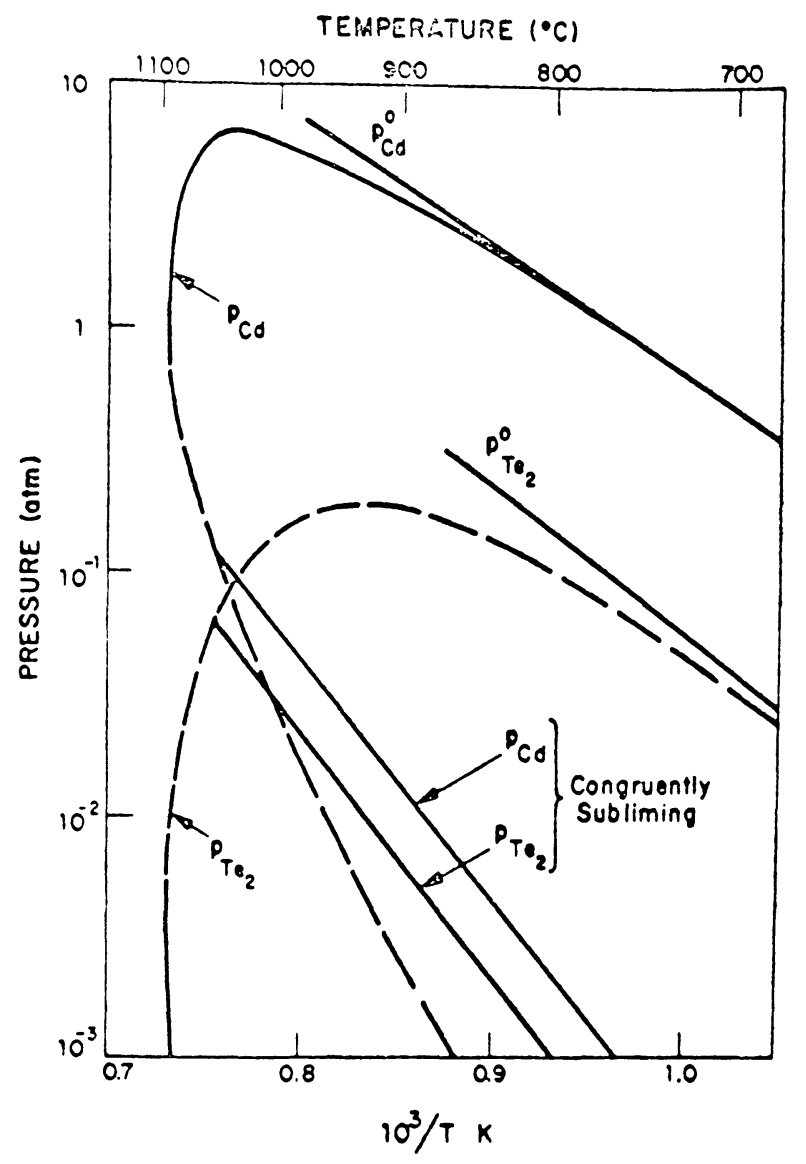

Fig. 1. - Cd and Te partial pressures as a function of $1 / \mathrm{T}$ for solid-liquid-vapour equilibrium in the Cd-Te system (after Strauss ref. [1]).

solution growth. Here one could engender constraints of constitutional supercooling which is not a featured topic for this paper.

3. Experimental solutions of the pressure problem. Growth techniques fulfilling the above fundamental constraints have been developed and are illustrated in figure 2. The vertical and horizontal Stockbarger and Bridgman techniques are illustrated diagrammatically as $2 a$ and $2 b$. They are classic solutions of the hot wall and $\mathrm{Cd}$ reservoir technologies noted above. The pulling technologies are depicted in figures $2 c$ and $2 d$. In figure $2 c$, which represents the Liquid Encapsulation technique a layer of encapsulant floating on the surface of the melt effectively provides a hot wall. This layer acts as a liquid seal provided the inert gas pressure on the surface of the encapsulant is greater than the dissociation pressure of the melt $(\sim 0.7 \mathrm{~atm})$. Successful experimental practice will be discussed later : it normally requires pressures considerably in excess of the dissociation pressure.

The method of LEC-growth involves a post-crystallization situation in which the solid cools down whilst coated by a thin film of encapsulant-assuming ideal conditions hold. Thus the solid cools in a constant composition environment. This is a desirable feature in certain circumstances. But, there are situations for II-VI compounds in general and for $\mathrm{CdTe}$ in particular where the ability to grow and cool down the crystal under a known easily-adjustable pressure of $\mathrm{Cd}$ or $\mathrm{Te}$ is needed. A growth technique that also makes use of the undoubted virtues of crystal pulling involving unconstrained growth from a stirred melt would be highly advantageous. In principle Pressure Balancing [5] can be adapted to a pulling mode and is designed to have an independent pressure control facility.

A diagramatic representation of the pressure balancing apparatus is shown in figure $2 d$. The crystal is pulled from a melt contained in the inner envelope or growth chamber 9 which is supported and surrounded by the main pressure chamber 7 . The pull rod passes through a normal seal in 7 and then through a liquid seal 18 contained in a well in the pull rod bearing seal block 8 . The nub of the technique is the means for maintaining the liquid seal in position. It is prevented from running down the pull rod under the action of gravity by the screwing action of the pull rod against a female screw thread 19 cut out of the hole in the bearing seal block 8. Any liquid between the rod and the thread is screwed back as in an Archimedes screw into the well, provided the rotation is in the upward sense. The liquid seal prevents diffusive loss of volatile species where the pull rod enters the growth chamber. Mechanical loss of volatile species by pressure differentials across the liquid seal is prevented by Pressure Balancing.

Pressure Balancing can be effected automatically by the two way bubbler 17 or by inert gas pressure regulation. In the latter case the cold growth chamber 9 is first evacuated. The system is then sealed by heating the encapsulant with the built-in heater situated in the pull rod bearing block. The charge is gradually heated and as the pressure $p_{\mathrm{g}}$ in the growth chamber tends to rise, the pressure rise is sensed by the liquid level sensor 16 . This sensor controls the valve 15 which can admit or release inert gas to or from the growth chamber. The pressure $p_{0}$ in the outer vessel 7 is thus automatically controlled to balance $p_{\mathrm{g}}$. The heater 13 can by suitable design be made to control the minimum temperature in the system, that is the temperature of the reservoir of the volatile species $(\mathrm{Cd})$. Thus in principle by regulating the reservoir temperature 13 one can control the pressure of the $\mathrm{Cd}$ in the environment during crystal growth and in the post-crystallization period. Furthermore one could readily record the actual vapour pressure of the Cd used during and after crystal growth.

This technique has been applied successfully to the growth of GaAs. Its further development has been somewhat curtailed by the availability of the simpler LEC technology. The advantage of having independent pressure control would seem to merit a reconsideration of the use of Pressure Balancing for CdTe. 

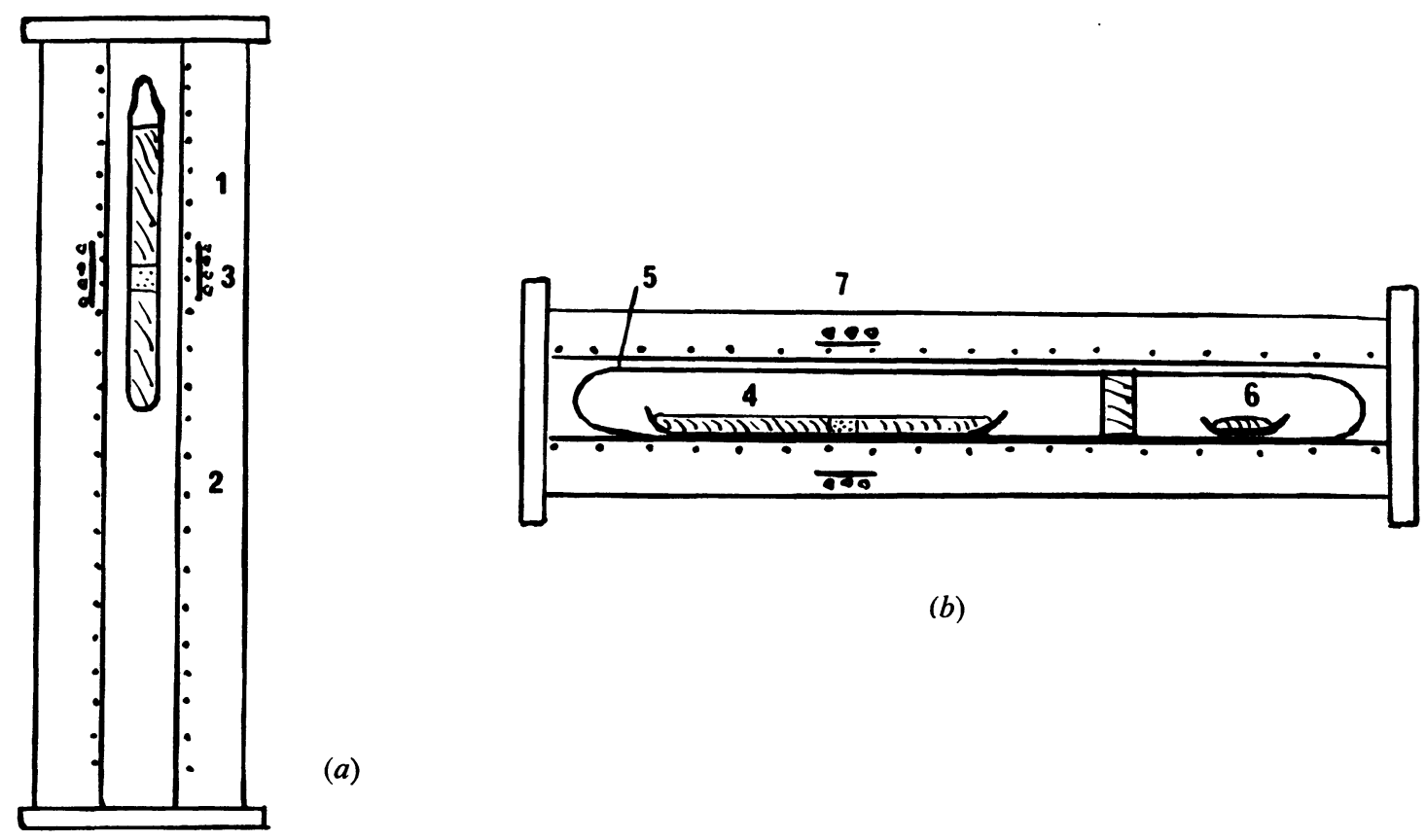

(b)

(a)

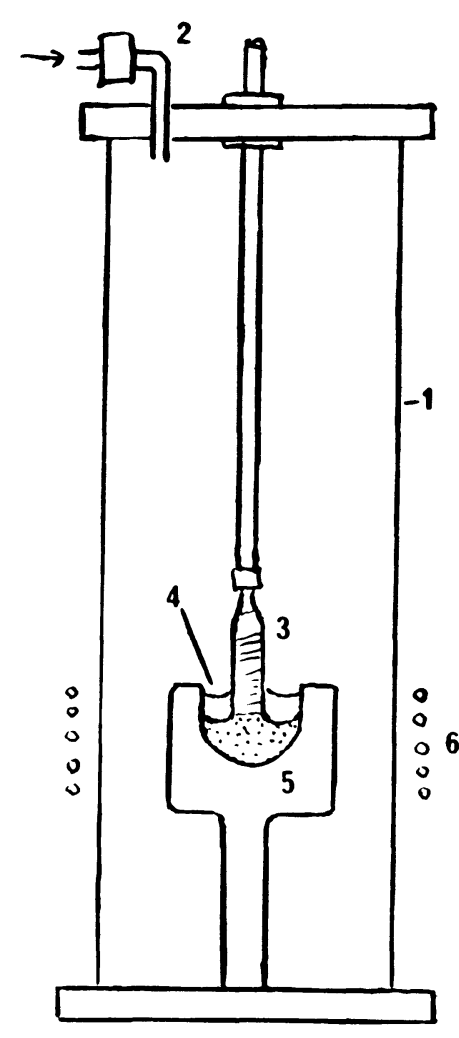

(c)

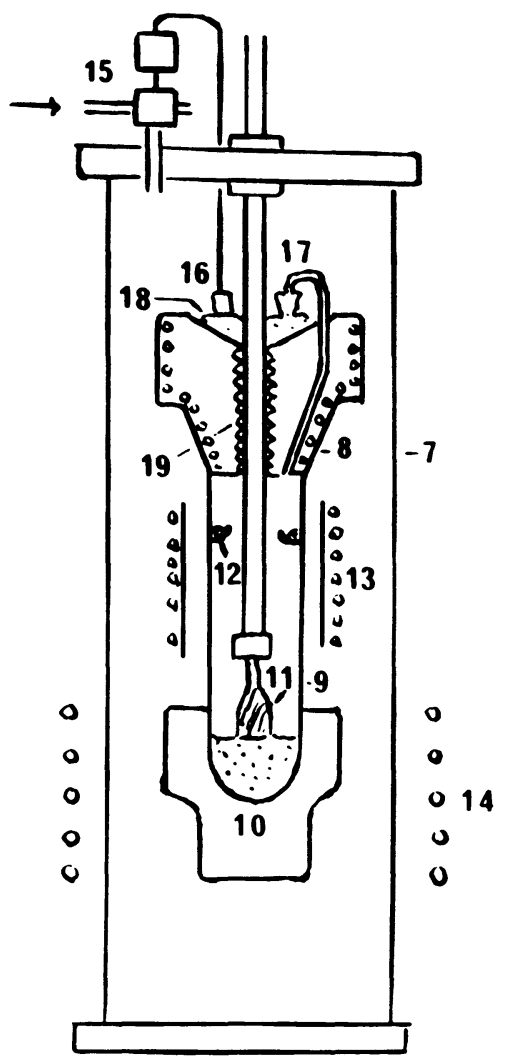

(d)

FIG. 2. - Techniques suitable for the growth of CdTe. a) Stockbarger/vertical Bridgman technique illustrating hot wall technology where the sealed tube is maintained at a temperature $\sim 728^{\circ} \mathrm{C}$ by heater 2 . The diagram depicts a zone pass modification of the original Stockbarger process which is strictly a normal freeze process. $b$ ) $\mathrm{Cd}$ reservoir technique where the $\mathrm{Cd}, 6$, is maintained $\sim 728^{\circ} \mathrm{C}$ for stoichiometric growth. c) LEC growth - conventional pulling with encapsulant 4. d) Pressure Balancing - described in text. 
4. Defects and the width of the solid phase field. There is ample evidence [6-9] that the properties of CdTe are influenced if not controlled by the chemical and thermal environment in the period following crystallization. Before discussing LEC-growth it is necessary to consider the potential concentration of defects which can be introduced into CdTe. There is a reasonable case for believing that the concentration and nature of defects are such that they actually influence the mode of crystal growth itself.

The most definitive early study that proposes a model for the solid phase field of CdTe is that of de Nobel [6]. This model was based on the vapour pressure data for $\mathrm{Cd}$ over CdTe and assumed the existence of various defect species. It showed a maximum solid phase width $\sim 10 \mathrm{ppm}$. It is appropriate to consider alternative perhaps more direct ways for revealing the magnitude of the solid phase width in CdTe. A combination of lattice parameter and density measurements is certainly more direct although even here there are problems of interpretation. It is possible nonetheless to show that the potential defect concentration in meltgrown CdTe crystals is very much greater than is indicated by de Nobel's model.

It is interesting to contrast the situation in CdTe with that in GaAs. Studies [10, 11] involving a systematic survey of very precise lattice parameter measurements on GaAs crystals that were grown by different methods have been made using an Apex system [12]. It was found possible to reproducibly measure the lattice parameter to one part per million (ppm), or to a factor of ten better if special precautions were taken. Since various phenomena indicate that the native point defect concentration in GaAs is of the order of $10^{19}$ defects per $\mathrm{cm}^{3}$ at the melting point it is in principle possible to compare GaAs grown at high temperatures (m.pt $1237^{\circ} \mathrm{C}$ ) with GaAs grown epitaxially at low temperatures $\left(750^{\circ} \mathrm{C}-850^{\circ} \mathrm{C}\right)$. The point defect concentration in epitaxially-grown GaAs would be expected to be orders of magnitude lower than in melt-grown crystals. The experimental results however showed that there was no difference in the lattice parameter of undoped GaAs specimens taken from crystals grown either from the melt, from $\mathrm{Ga}$ solution or from the vapour phase. The mean value representing each growth technique was $5.65325 \pm 0.00002$ at $27^{\circ} \mathrm{C}$. Driscoll and Willoughby [13] have also shown that GaAs specimens that were rapidly chilled from $1164{ }^{\circ} \mathrm{C}$ to room temperature did show a $28 \mathrm{ppm}$ increase over the standard lattice parameter but this deviation reduced to near zero in about 72 hours. It is argued that this lattice dilation is caused by Frenkel defects in the As sub-lattice [13, 14]. This evidence might also indicate the presence of Ga Frenkel defects.

Lattice parameter measurements [2, 15-17] on CdTe show a different pattern of behaviour to those on GaAs. The results of measurements by Kiseleva et al. [15] and by Kyle [2] show large ( $>100 \mathrm{ppm}$ ) apparently permanent differences in the values of the lattice parameter for CdTe prepared by different methods. These differences are however larger than those recently reported by Vaipolin et al. [17]. Kiseleva et al's results showed an apparent correlation of the measured lattice parameter with the free carrier concentration found in samples. Further, the difference in density obtained from weight measurements and X-ray measurements was used to deduce vacancy concentrations in high $n$ and $\mathrm{p}$ type material. These concentrations were 2.0 and $5.7 \times 10^{19}$ per $\mathrm{cm}^{3}$ respectively. This method of interpretation relies on differences between two almost equal quantities that stretched the measurement accuracy of experimental and fundamental parameters to the limits. That vacancies should contract the lattice parameter is questionable. There are contrary viewpoints $[18,19]$ but it is not the purpose of the present paper to discuss those here. An alternative simpler way of looking at the results and one that gives a useful guide to defect density differences is to normalise the lattice parameter deviations in units of $\Delta a / a_{0}$ where $a_{0}$ is a convenient reference value. A vacancy or interstitial is unlikely to reduce the lattice parameter by more than one normalised lattice parameter (NLP) unit or increase it by more than a few NLP units at the most. Values of $\Delta a / a_{0}$ can thus be used to compare defect density differences with a view to assessing the order of magnitude of the maximum phase width. Further since there are likely to be positive and negative deviations associated with different defects $\Delta a / a_{0}$ will probably underestimate defect density differences and hence phase widths from suitably selected material.

Kiseleva et al. [15] and Kyle's [2] results are shown in table I. It is misleading to compare the results by the various authors for any one method of preparation since the exact method of preparation particularly the thermal histories are probably not comparable. It seems at this stage of our understanding worth establishing the extremes of lattice parameter difference found by the various authors.

The maximum NLP difference found by Kiseleva et al. [15] was $602 \mathrm{ppm}$ between a Bridgman-grown crystal and a crystal grown from excess Cd. In Kyle's [2] experiments the maximum NLP difference was $448 \mathrm{ppm}$ between crystals grown from $\mathrm{Cd}$ and $\mathrm{Te}$ solutions. Viapolin et al. [17] however considered that their lattice parameter measurements on variously-grown $\mathrm{CdTe}$ were the same within experimental error. His mean value of $6.4818 \pm 0.0003$ would thus indicate a maximum variation of less than $100 \mathrm{ppm}$ in the NLP. Nevertheless a larger NLP difference can be seen in the extreme values recorded in his results. If one unit of lattice parameter gave rise to one defect and say one free carrier, then, the maximum deviations found by the respective authors Kiseleva et al. and Kyle would be 1.7 and $1.3 \times 10^{19}$ NLP defects or carriers per $\mathrm{cm}^{3}$. Such large NLP defect density differences clearly support a view that the maximum solid phase width in 
TABLE I

Effect of growth conditions on the lattice parameter of $\mathrm{CdTe}$

\begin{tabular}{|c|c|c|}
\hline $\begin{array}{l}\text { Growth } \\
\text { technique }\end{array}$ & $\begin{array}{l}\text { Growth } \\
\text { environment }\end{array}$ & $\begin{array}{c}\text { Lattice } \\
\text { parameter } \\
(\AA) \\
\end{array}$ \\
\hline Bridgman & $\mathrm{Cd}\left({ }^{*}\right), 730^{\circ} \mathrm{C} \sim 0.7 \mathrm{~atm}$ & 6.4802 \\
\hline Bridgman & $\mathrm{Cd}(*), 800^{\circ} \mathrm{C} \sim 1.5 \mathrm{~atm}$ & 6.4840 \\
\hline Bridgman & $\mathrm{Cd}\left({ }^{*}\right), 845^{\circ} \mathrm{C} \sim 2.3 \mathrm{~atm}$ & 6.4803 \\
\hline Bridgman & & 6.4805 \\
\hline Solution & xs $\mathrm{Cd} 850^{\circ} \mathrm{C}$ & 6.4801 \\
\hline Solution & xs Cd & 6.4794 \\
\hline Solution & Te-rich & 6.4823 \\
\hline
\end{tabular}

CdTe is at least an order of magnitude greater than originally suggested by de Nobel. But, more precise measurements on equilibrated specimens with known thermal histories will be needed to fully substantiate this implication.

5. Liquid encapsulated growth. - Meiling and Leombruno have reported attempts at the LEC-growth of CdTe. In an abstract account [20] of their work they reported great difficulty in growing crystals larger than $5 \mathrm{~mm}$ in diameter. This was attributed in part to the poor thermal conductivity $\left(0.0580 \mathrm{~W} \mathrm{~cm}^{-1} \mathrm{deg}^{-1}\right.$ at $32.7^{\circ} \mathrm{C}(21)$ ) of CdTe. Vandekerkof [4] also reported this problem. Additionally, he found difficulties with $\mathrm{Cd}$ loss from the periphery of the crystal and with discoloration of the $\mathrm{B}_{2} \mathrm{O}_{3}$. Klausutis et al. [21] however were able to grow polycrystalline boules of $\mathrm{CdTe}_{1-x} \mathrm{Se}_{x}$ ( $x$ from 0.05 to 0.15 ) without either of the above difficulties. They grew their crystals using an over-pressure of $20 \mathrm{~atm}$ of $\mathrm{Ar}$ in their pulling chamber. But, they noted $\mathrm{Cd}$ vapour losses occurred below a pressure of $13 \mathrm{~atm}$. In the authors' experience with CdTe, vapour losses occurred when the pressure fell below $\sim 5 \mathrm{~atm}$.

In the present investigation the procedure for optimising the growth conditions to obtain control of diameter of the crystals was found to be more critical and time consuming than for example the equivalent procedure for GaAs or InP. This was a consequence of the lower temperature gradients which develop in the solid at the solid-liquid interface with CdTe compared with $\mathrm{GaAs}$ or InP. The ratio of the thermal conductivity of CdTe to that of GaAs for example is $\sim 0.11$ at room temperature and $\sim 0.35$ at their melting points.

In almost all the pulls to date the $\mathrm{B}_{2} \mathrm{O}_{3}$ layer remained either perfectly clear (most cases) or adequately clear. In the case of the III-V compounds [22] poor visibility is generally attributed to traces of water in the $\mathrm{B}_{2} \mathrm{O}_{3}$ and fairly stringent control of the preparation of
$\mathrm{B}_{2} \mathrm{O}_{3}$ is necessary to overcome this problem [23]. $\mathrm{Bu}$ there is likely to be more than one cause of cloudiness. Prolonged contact of the molten elements $\mathrm{Cd}$ and $\mathrm{Te}$ with $\mathrm{B}_{2} \mathrm{O}_{3}$ in the process of forming the compound (see below) has been found to cause cloudiness of the $\mathrm{B}_{2} \mathrm{O}_{3}$.

Most of the crystals were prepared in two stages. In the first stage appropriate amounts of $\mathrm{Cd}$ and $\mathrm{Te}$ were reacted together under $\mathrm{B}_{2} \mathrm{O}_{3}$ under a pressure of $\sim 27 \mathrm{~atm} \mathrm{~N}_{2}$ gas. After cooling down, the CdTe was extracted by dissolving the $\mathrm{B}_{2} \mathrm{O}_{3}$ with hot distilled water. In the second stage, the pulling procedure, the etched and dried preformed-charge of $\mathrm{CdTe}$ was placed in a silica crucible and covered with $\mathrm{B}_{2} \mathrm{O}_{3}$ pellets. The seeds used initially were polycrystalline sections of preformed or prepulled crystals. Later, single crystal sections from CdTe prepared by the solvent evaporation process [24] were used. The charge was melted down and the seeding and growth carried out in the conventional manner. The pull rates were typically $0.5 \mathrm{~cm}$ per $\mathrm{hr}$ and the seed rotation rate was $10 \mathrm{rpm}$. Crucible rotation was not used. Reasonably-shaped crystals could be obtained by manual control but the crucible position relative to the coil was very critical. The depth of $\mathrm{B}_{2} \mathrm{O}_{3}$ was a compromise. Too shallow a depth resulted in an inadequate layer of $\mathrm{B}_{2} \mathrm{O}_{3}$ being drawn up with the crystal, resulting in Cd loss from the surface of the pulled crystal. Too great a depth produced characteristically bulbous shaped crystals whose diameter gradually increased and decreased in a periodic manner. In the equivalent situation in GaP Nygren [25] has shown that the repeat period correlates with the depth of $\mathrm{B}_{2} \mathrm{O}_{3}$. A thickness of $\mathrm{B}_{2} \mathrm{O}_{3}$ around $7 \mathrm{~mm}$ permitted adequate control of crystal diameter. Completely single crystals have not yet been grown, although occasionally almost the whole of the crystal section was single with three or four boundaries just at the edge of the section. Examples of LEC crystals are 


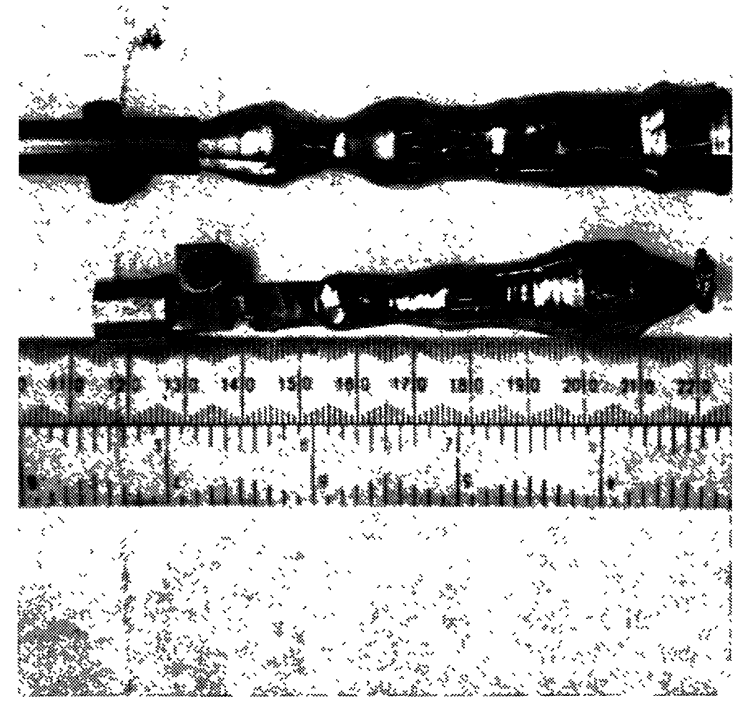

FIg. 3. - Two LEC-CdTe crystals showing. a) Necking procedure (left crystal). $b$ ) Bulbous growth (see text) followed by reasonable diameter control.

shown in figure 3 . The current state of the art then is one of characterising the crystal defects identifying their causes, and developing procedures for preventing them.

6. Crystalline defects and their characterization. - 6.1 Boundaries, TWINS, DISLOCATIONS AND PRECIPITATES. - Boundaries. - The major visible defects were boundaries which separated individual single crystal grains. They were generally visible on the outside of the crystals. The separate single crystal regions were easily identified by viewing a lightlyground and obliquely-illuminated surface under a low magnification binocular microscope. The tiny cleavage planes in each single crystal grain produced marked contrast changes in the reflected light intensity as the specimen was gradually rotated. Suitable etches like 1 vol $48 \% \mathrm{HF}: 3$ vols conc $\mathrm{HNO}_{3}: 4$ vols $2 \%$ aqueous $\mathrm{AgNO}_{3}$ [26] could equally produce good visible contrast between grains. Figure 4 shows an example of a section of a crystal of quite poor crystalline quality.

Two types of boundary were identified, low angle grain boundaries and twin boundaries. The presence of low angle grain boundaries is very significant. Backreflection Laue photographs taken from the surfaces adjacent to low angle boundaries showed that the angle of misorientation was less than a degree. The twin boundaries are very distinct in that $a$ ) they appeared to be almost always lamellar twins and $b$ ) they intersected the cut surfaces in parallel lines and were thus readily

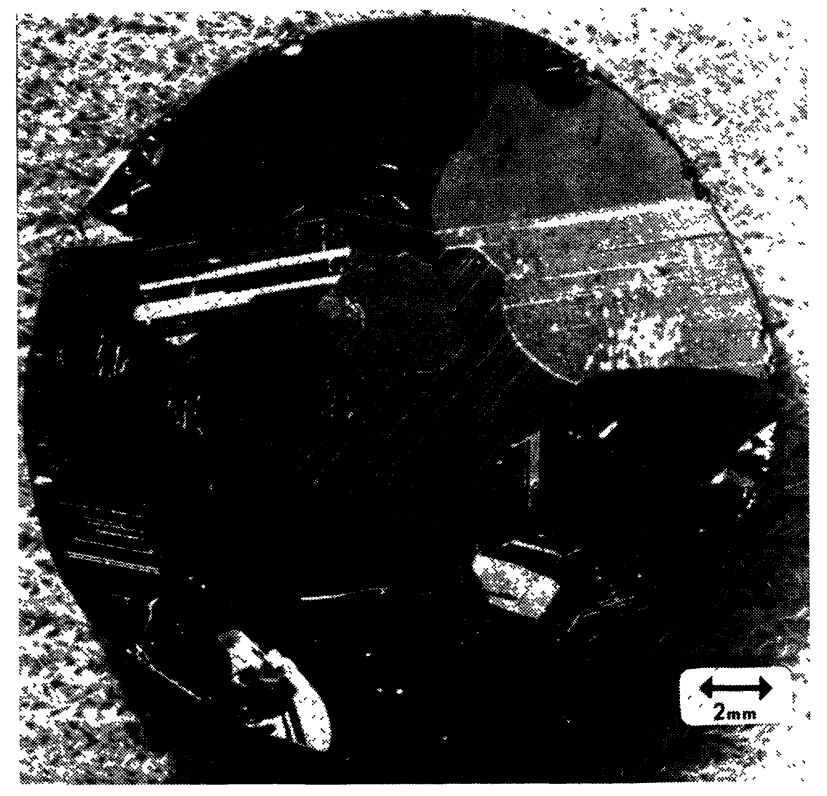

FIG. 4. - Etched cross-section of a poor LEC-crystal showing low angle grain boundaries and lamellar twins.

distinguishable from low angle grain boundaries which gave curved intersections. Examples of both low angle grain boundaries and twins can be seen in figure 4 .

Twins. - The twin boundaries are apparently always of the lamella variety [27], that is they appear to originate and propagate in pairs. Interesting examples can be seen in figure 5 where the direction of inter-

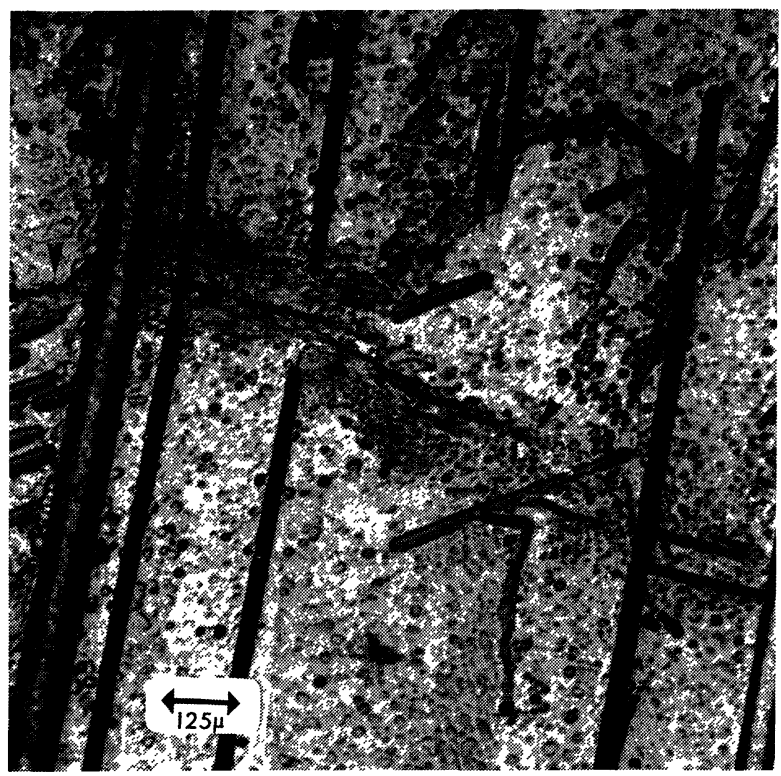

FIG. 5. - Photomicrograph of a section of an LEC crystal showing a low angle boundary (marked with arrows). On the left of the photomicrograph the intersections of the four sets of lamellar twins with the flat surface of the specimen deviate from a straight line trace at the boundary due to the angular misorientation of the lattice caused by the boundary. 
section of the twins is caused to deviate by the low angle boundary which crosses it. The angular misorientation between the single crystal grains is thus evident. The formation of twins can be understood in principle [27]. A mis-nucleation event on the growth surface that produces a change in the lattice orientation relative to the original growth surface will produce a new region of growth that meets the region of growth corresponding to normal nucleation on at least two surfaces. A crystallographically favourable situation for the surfaces to mate is a twin plane of the type $\{111\}$. The composition plane of the boundary would then be coherent.

Dislocations. - Dislocations were revealed using the previously-noted grain boundary etchant [26]. The etch pit densities were moderately high, but naturally variable. This is understandable since there was evidence of polygonisation. Typical densities were of the order of $1-4 \times 10^{5}$ per $\mathrm{cm}^{2}$.

Precipitates. - Precipitates have been observed in slices of crystals when viewed by IR-transmission microscopy. Precipitates appear to be a feature of LEC-CdTe grown from substantially stoichiometric melts. The precipitates occur mainly in grain boundaries although they are by no means confined to them. It has also been noted that regions between certain intersections of some grain boundaries were apparently free of precipitates; this has been noted in other crystals [28]. The precipitates appear as individual elongated opaque particles which when brought into focus at high magnification do not have any obvious crystalline structure. They are about $\sim 1 \mu \mathrm{m}$ in diameter and are typically present in grain boundary sections at a volume concentration of $\sim 5 \times 10^{7}$ per $\mathrm{cm}^{3}$. Figure 6 shows typical precipitates within, and close to, a grain boundary. Figure 7 shows an SEM photomicrograph of precipitates in a section of a grain boundary marked $\mathrm{AB}$ and $\mathrm{BC}$. It is evident from the micrograph that only part $A B$ of the grain boundary has any precipitates. The feature $\mathrm{X}$ in figure 7 is $\sim 1 \mu \mathrm{m}$ in diameter. A $10 \%$ higher count rate for Te was found in precipitate $X$ when compared with the bulk CdTe. Equivalent results have been found in another crystal. No evidence of this type of precipitate has been detected using IR-transmission microscopy in non-LEC CdTe grown from either excess Cd solution by solvent evaporation or from excess Te solution by the THM method.

Preliminary studies have also been made on LEC crystals grown from melts containing excess $\mathrm{Cd}$ or Te. Precipitates were observed in 1 at \% excess Cd crystals ( 2 examined) but not in the 2 at $\% \mathrm{Cd}$ excess crystals ( 3 examined). Crystals grown using 1 and 2 at $\%$ excess Te (1 crystal of each examined) appeared to show a marked reduction in the precipitate concentration but there was no obvious change in the grain structure. The precipitate results are consistent with Strauss's

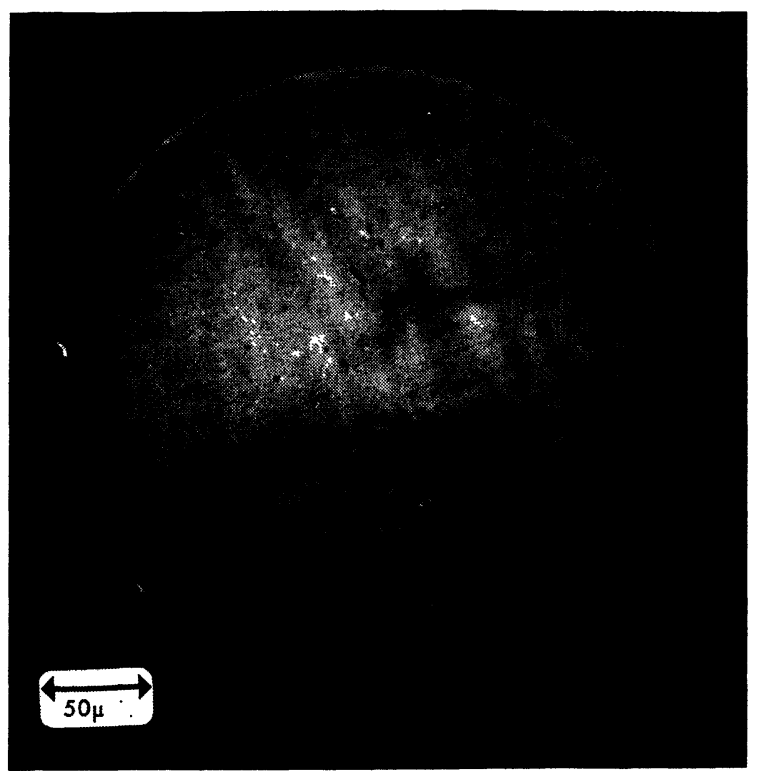

FIG. 6. - IR transmission photomicrograph showing precipitates concentrated along a grain boundary. Dispersed precipitates can also be seen at different heights ie in and out of focus.

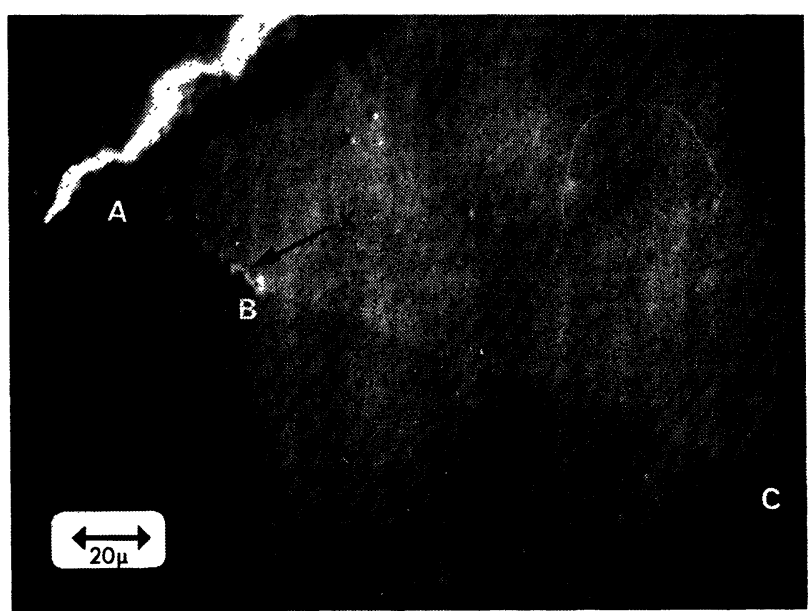

FIG. 7. - Scanning electron microscope photomicrograph showing a grain boundary $A B C$. Ignore the large scratch artefact above $A$. Note the pricipitates along $A B$ but not $B C$. Precipitate $\mathrm{X}$ showed a $10 \%$ higher than average Te count when analysed using $\mathbf{X}$ ray emission.

suggestion [1] at the last CdTe symposium that the solid phase field lies on the Te-rich side of the phase diagram not on the Cd-rich side, but the results do not constitute a proof of this suggestion.

Discussion. - The presence of low angle grain boundaries has not to our knowledge been noted as a characteristic difference between melt-grown CdTe (and other II-VI's) and the III-V's. The grain boundaries in InSb for example have been systematically investigated by Haasen [29] and almost all the boundaries in a crystal have been shown to be coherent; the lattice orientation between adjacent single crystal 
grains bore a characteristic twin relationship. Low angle grain boundaries have not to our knowledge been reported in undoped InSb or in the undoped III-V's. Since their presence in CdTe crystals is a real hindrance to progress it is important to question their origin. They are a feature of metallic crystals but we can find no explanation for their origin from metallurgy.

We frankly do not know the origin of low angle grain boundaries but would suggest the following speculative model based on a comparison between $\mathrm{GaAs}$ and $\mathrm{CdTe}$. Both compounds have similar lattice structures, bonding energies and melting points. Diffusion in CdTe however is orders of magnitude greater than in GaAs. CdTe would appear to have a higher point defect concentration (involving vacancies) than $\mathrm{GaAs}$ at comparable temperatures. Low angle dislocation boundaries are common in undoped CdTe but not in undoped GaAs. But the density of dislocations found in CdTe cannot explain the low angle grain goundaries. The dislocation densities could only account for misorientations of seconds of arc.

However, the presence of impurities and precipitates in grain boundaries does suggest the possibility that the impurities and vacancies are connected. Vacancy impurity complexes could, it is postulated, have high enough mobilities and be present in sufficient concentration to propagate low angle grain boundaries. Vacancy impurity complexes would probably migrate in the direction of the applied temperature gradient. The significance of interface shape could then be crucial. A concave growth front would have a temperature distribution which would tend to cause vacancy impurity complexes to concentrate towards the centre of the crystal where they could feed and perhaps even initiate low angle boundaries. A convex growth surface could be helpful in avoiding low angle grain boundaries since this would tend to prevent the complexes concentrating and tend to disperse them to the edge of the crystal. Growth at low temperatures by epitaxy or from solution could also be helpful.

6.2 ImPURITIES. - The scope for achieving additional purification by pulling is strictly limited since the crystallization process involves only a single normal freeze. Indeed, to stand any chance of pulling pure $\mathrm{CdTe}$ one requires high purity starting material. The crucial question with melt-growth is whether one can avoid contaminating the original starting material.

The starting materials for the LEC growth of CdTe were as noted previously the elements themselves. Both the $\mathrm{Cd}$ and $\mathrm{Te}$ were subjected to two zone refining operations $\left({ }^{*}\right)$, the middle section from the first zone refining being used for the second zone refining operation. The $\mathrm{B}_{2} \mathrm{O}_{3}$ was a grade $\left({ }^{* *}\right)$ purified by recrystallisation.

The pulled crystals were analysed by mass spectrometric analysis using an AEI MS702R instrument. Unfortunately $\mathrm{Cu}$ and some of the transition elements have limited sensitivity because of interference from isotopes of the matrix elements. In the event however the more serious problem arises from $\mathrm{B}$ and $\mathrm{Br}$ contamination. Typical analyses of $\mathrm{CdTe}$ grown from substantially stoichiometric melts are shown in table II. The $\mathrm{Br}$ contamination was traced to the $\mathrm{Br}_{2}-\mathrm{CH}_{3} \mathrm{OH}$ etch which was used to clean up the preformed CdTe charge after it had been extracted from contact with $\mathrm{B}_{2} \mathrm{O}_{3}$. Minute fissures and cracks in the CdTe charge are a trap for etchant which is difficult to wash clear. This problem is nevertheless potentially soluble.

The $B$ contamination was expected. Boron is a potential donor in $\mathrm{CdTe}$, hence the ability to control the $B$ concentration in LEC crystals may be desirable depending on the use or device application envisaged for the material. The addition of oxides (eg CdO) to the $\mathrm{B}_{2} \mathrm{O}_{3}$ is a potential way of reducing $B$ contamination. This and other methods have not yet been investigated.

6.3 EleCtrical CHARACTERIZATION. - The Hall effect and conductivity of specimens cut from LECcrystals were measured using the van der Pauw technique. Ohmic contacts to the n-type material were straightforward. They were achieved by alloying in In dots at around $170^{\circ} \mathrm{C}$. Contacts to high resistivity

(*) MCP (Electronics) Ltd., Alperton Wembley Middlesex. $(* *)$ BDH Chemicals Ltd., Poole, Dorset.

TABLE II

Chemical analysis (*) of LEC-CdTe in ppma

\begin{tabular}{|c|c|c|c|c|c|c|c|c|}
\hline $\begin{array}{l}\text { Element } \\
\text { crystal } \\
\text { No }\end{array}$ & B & $\mathrm{Br}$ & $\mathrm{Zn}$ & As & Al & $\mathrm{Ag}$ & $\mathrm{Ba}$ & $\mathrm{K}$ \\
\hline - & $\overline{11}$ & $\overline{12}$ & $\overline{0}$ & $\overline{0} 06$ & $\overline{0} 08$ & $<0.06$ & 0.05 & \\
\hline $\begin{array}{l}\text { CT } 016 / 28 \\
\text { СТ } 037 / 65\end{array}$ & $\begin{array}{r}11 \\
4\end{array}$ & $\begin{array}{c}12 \\
2.3\end{array}$ & $\begin{array}{l}0.3 \\
0.15\end{array}$ & $\begin{array}{c}<0.06 \\
0.1\end{array}$ & $\begin{array}{r}0.08 \\
<0.08\end{array}$ & $\begin{array}{r}<0.06 \\
0.05\end{array}$ & $\begin{array}{l}0.05 \\
0.04\end{array}$ & $\begin{array}{l}0.2 \\
0.045\end{array}$ \\
\hline СТ 040/14 & 15 & 4.3 & 0.15 & 0.1 & $\leqslant 0.3$ & $<0.05$ & 0.055 & 0.015 \\
\hline СТ 040/36 & 5 & 2.6 & 0.15 & 0.1 & $<0.08$ & $<0.015$ & 0.025 & 0.009 \\
\hline
\end{tabular}

$\left(^{*}\right)$ Most elements $<0.025$ except Ta, $I<0.8 ; \mathrm{S}, \mathrm{Si}, \mathrm{Mg}<0.25 ; \mathrm{Sn}, \mathrm{Na}, \mathrm{Mo}<0.1 ; \mathrm{Mn}, \mathrm{Fe}, \mathrm{Ni}, \mathrm{Cu}$, matrix interference, $\mathrm{C}$, $\mathrm{O}, \mathrm{N}$ not determined. 
TABLE III

Some typical electrical/chemical characteristics of LEC-CdTe crystals

\begin{tabular}{|c|c|c|c|c|c|}
\hline \multirow[t]{2}{*}{$\begin{array}{c}\text { Crystal } \\
\mathbf{N}^{\circ}\end{array}$} & Carrier: & per $\mathrm{cm}^{3}$ & $\begin{array}{c}\text { ctrical prope } \\
\text { Resistivity } \\
\Omega \mathrm{cm}\end{array}$ & $\begin{array}{r}\mathrm{M} \\
\mathrm{cm}^{2}\end{array}$ & \\
\hline & $295 \mathrm{~K}$ & $77 \mathrm{~K}(* *)$ & $295 \mathrm{~K}$ & $295 \mathrm{~K}$ & $77 \mathrm{~K}$ \\
\hline$\overline{01}$ & - & - & - & - & \\
\hline СТ 016/25 & $4.3 \times 10^{17}$ & $4.1 \times 10^{17}$ & $2.2 \times 10^{-2}$ & 646 & 597 \\
\hline СТ O37/65 & $3.5 \times 10^{17}$ & - & $5.9 \times 10^{-1}$ & 83 & - \\
\hline СТ 040/36 & $3.1 \times 10^{17}$ & $2.5 \times 10^{17}$ & $8.2 \times 10^{-2}$ & 248 & 731 \\
\hline CT 103 & $1.5 \times 10^{16}$ & - & $4.3 \times 10^{-1}$ & 922 & - \\
\hline CT 104 & $2.2 \times 10^{16}$ & - & $2.9 \times 10^{-1}$ & 965 & - \\
\hline CT $122\left(^{*}\right)$ & $7.4 \times 10^{15}$ & & & 584 & \\
\hline
\end{tabular}

\author{
Chemical properties

\begin{tabular}{|c|c|}
\hline \multicolumn{2}{|c|}{$\begin{array}{l}\text { Major impurities } \\
\text { Atoms per } \mathrm{cm}^{-3}\end{array}$} \\
\hline $2 \times 10^{17}(\mathrm{~B})$ & $10^{17}(\mathrm{Br})$ \\
\hline $2 \times 10^{17}(\mathrm{~B})$ & $6.6 \times 10^{16}(\mathrm{Br})$ \\
\hline $.4 \times 10^{17}(\mathrm{~B})$ & $7.5 \times 10^{16}(\mathrm{~B}$ \\
\hline
\end{tabular}

$\left.{ }^{*}\right) 1$ at $\%$ excess Te added to CdTe melt. $(* *)$ all n-type.

p-type CdTe were not so reliable. The most useful technique following literature practice [6] has been to plate $\mathrm{Au}$ on the surface and then contact the Au with In.

The results for typical specimens are reproduced in table III. The carrier concentrations found in crystals grown from substantially stoichiometric melts were around the $10^{16}-10^{17}$ carriers per $\mathrm{cm}^{3}$ level. These extrinsic carrier concentrations correlate with the impurity concentrations determined by MS7 analysis within the accuracy of the chemical analyses. Mass Spectrometric analysis is usually reliable to a factor of \pm 3 , although experience has shown the results for well behaved elements may well be more accurate. It is interesting that the $\mathrm{B}$ and $\mathrm{Br}_{2}$ concentrations are virtually the same in each crystal. Hence, within the limits of experimental error, either $\mathrm{B}$ or $\mathrm{Br}_{2}$ or the sum effect of both elements could account for the free electron concentration in the crystals. The $77 \mathrm{~K}$ mobilities for all the specimens, even those with the fewest apparent free carriers, are lower than the best previously quoted [30] results for uncompensated CdTe.

The results of measurements on crystals grown from melts containing significant amounts of excess $\mathrm{Cd}$ or excess Te were not clear cut. The crystals certainly had different properties to those grown from near stoichiometric melts. Further, it was generally found difficult to prepare specimens with van der Pauw contacts which were all truly ohmic when tested at high current densities and low temperatures. Considerable effort was expended in endeavouring to get reliable results on different specimens from different crystals. Most of the specimens appeared to be p-type and of moderate resistivity but until the material is more fully characterised metallurgically the cause of the measurement difficulties cannot be established. Similar problems were encountered with the Te-excess crystals, with the exception of the crystal grown with $1 \%$ excess Te. This had properties similar to the crystals grown from stoichiometric melts.

6.4 Photoluminescence Characterization. - The photoluminescence spectra of $\mathrm{CdTe}$ have not yet been adequately calibrated as a means for identifying che- mical impurities and impurity complexes in CdTe. In the case of GaAs a systematic study [31] has characterised the common elements which can behave as acceptors in the crystal. But, for identification purposes it is necessary that the GaAs be sufficiently pure, less than $\sim 10^{16}$ carriers per $\mathrm{cm}^{3}$ for $p$-type material and less than $\sim 10^{15}$ carriers per $\mathrm{cm}^{3}$ for $\mathrm{n}$-type material, and further the GaAs should be of good crystal perfection. In situations where the crystals are less pure and less perfect the photoluminescence spectrum can serve as a useful guide to the quality of the material. In the following section therefore some results are discussed on the photoluminescence spectra of LEC-CdTe and some observations are made on how these spectra compare with spectra recorded from CdTe prepared by other growth techniques.

The basic features of the photoluminescence spectrum of CdTe can be appreciated from a simplified materials viewpoint by considering three principal regions. There are exciton lines within about $20 \mathrm{meV}$ of the band edge. There are various lines in the region $\sim 1.53-1.55 \mathrm{eV}$ some of which are attributed to donor/acceptor transitions involving the cadmium vacancy and there is an emission band around $1.40 \mathrm{eV}$ with strong classical phonon replicas showing a Poisson distribution in energy.

The first notable characteristic of LEC crystals is that they do not show sharp exciton lines. Structure in the exciton spectra is normally only a feature of purest crystals possessing the best physical quality. Material grown at low temperatures from Te solution has revealed the best exciton spectra we have seen so far.

The most impure crystals, those with free electron concentrations around $3 \times 10^{17}$ electrons per $\mathrm{cm}^{3}$, emitted a broad luminescence band around $1.4 \mathrm{eV}$ showing little or no significant structure. An example of the luminescence spectra from a purer good average crystal is shown in figure 8. At $5 \mathrm{~K}$ one can see near the band edge the donor exciton line at $1.5913 \mathrm{eV}$ together with the acceptor exciton line at $1.5884 \mathrm{eV}$ line $[32,33]$. The lines labelled $A_{0}, B_{0}$ and $C_{0}$ together with phonon replicas at $E_{x}-(n x 0.021) \mathrm{eV}$ are believed to be due to acceptors. They are pair bands associated with $D / A$ 


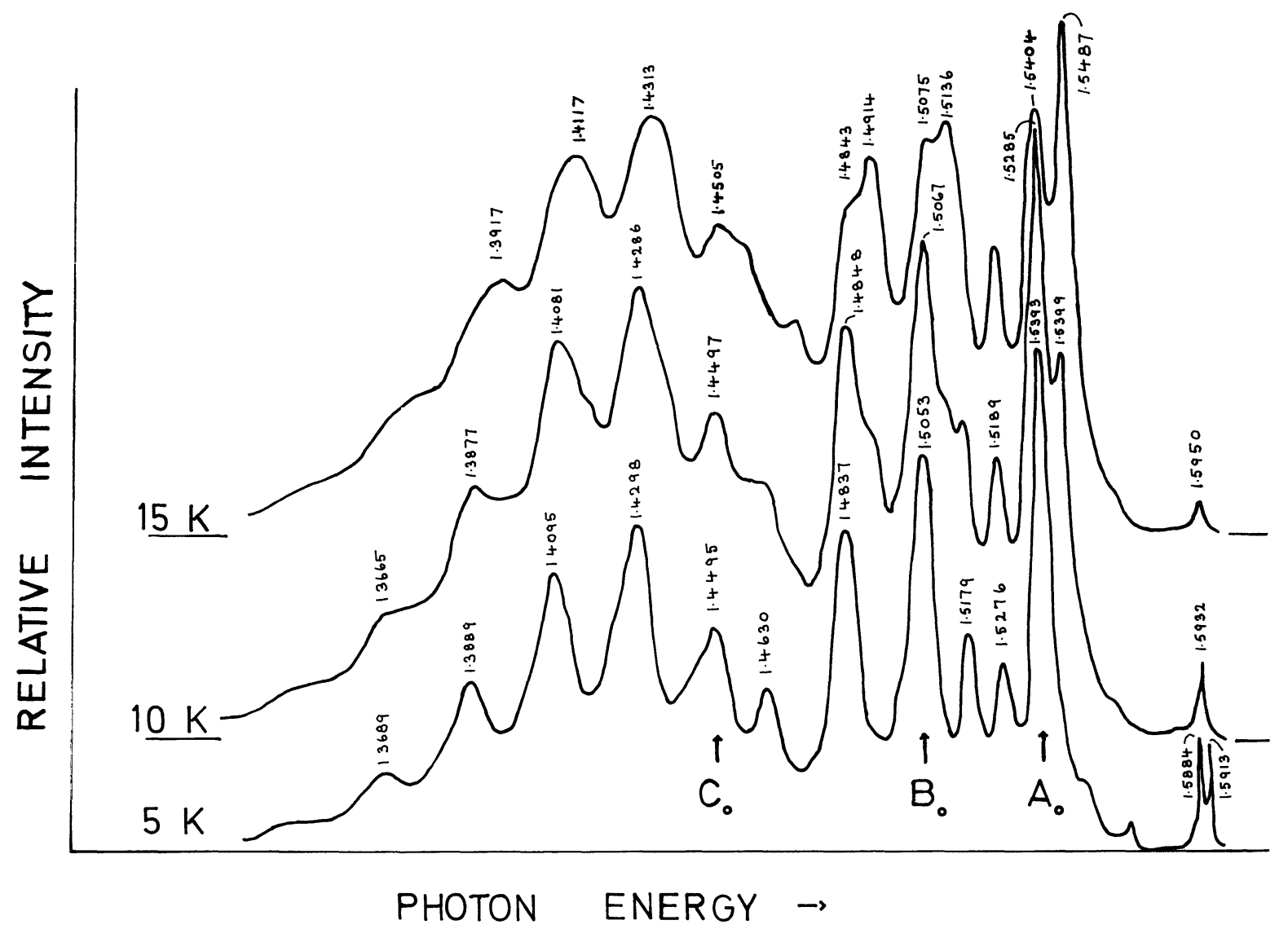

FIG. 8. - Photoluminescence spectra taken from an LEC crystal showing the effect of increase of temperature. $A_{0}, B_{0}$ and $C_{0}$ are believed to be pair bands due to acceptors. Their phonon replicas at $E_{x}-n 0.021 \mathrm{eV}$ can also be seen. Increasing the temperature from $5 \mathrm{~K}$ to $10 \mathrm{~K}$ and $15 \mathrm{~K}$ progressively reveals the $\mathrm{FB}$ transitions associated with the pair bands.

pairs. The corresponding free-to-bound peaks can be progressively revealed by taking spectra at higher temperatures as shown in figure 8 . These lines are not new, the consensus view of the $A_{0}$ pair line being that it is associated with the Cd vacancy.

The $C_{0}$ line and its associated replicas constitute the $1.4 \mathrm{eV}$ emission band mentioned earlier. The intensity of this band is sensitive to the conditions of crystal growth. The band is virtually absent in crystals prepared by evaporation of cadmium from cadmium-rich melts. Agrinskaya et al. [34] consider that the band is connected with the formation of $\mathrm{V}_{\mathrm{Cd}^{-}}$-donor complexes. The present results do not conflict with this viewpoint. Certainly the $C_{0}$ band is strong in CdTe grown from Te-rich solutions. A more detailed analysis of these spectra will be reported elsewhere.

7. Conclusions. - At the present stage of development the LEC technique can be used for growing crystals with at best large single crystal grains say $10 \mathrm{~mm} \times 5 \mathrm{~mm} \times 50 \mathrm{~mm}$. The major hindrance to the growth of large single crystals would appear to involve understanding and controlling the formation of low angle grain boundaries and twins. Like other meltgrowth techniques it does not produce the purest crystals, which in the semiconductor field are now achieved by growth at lower temperatures. Provided $B$ contamination is not a problem or can be controlled the LEC technique does offer scope for the ready production of doped material for various studies.

In cases where crystals need to be prepared in a controlled $\mathrm{Cd}$ or Te atmosphere a pulling technology involving Pressure Balancing is suggested as a method with potential merit.

Acknowledgments. - The authors gratefully acknowledge the help, skill and perseverance of Mr. G. W. Blackmore and Mr. C. D. Dowding of the Admiralty Materials Laboratory who provided the mass spectrometric analyses, Mr. D. G. Coates who carried out the scanning electron microscope investigations, of Miss A. Royle, Mr. S. Benn and Miss S. Stephenson who made the electrical measurements, of Mr. C. Burford who assisted in the growing of crystals and Mrs. M. Webb who recorded and measured up the photoluminescence spectra. We are as ever indebted to valuable discussions on various aspects of the work with our colleagues but especially with Dr. P. J. Dean and Dr. A. M. White for definitive discussions on the photoluminescence spectra.

Copyright (C) Controller HMSO London 1976. 


\section{References}

[1] Strauss, A. J., Proc. of the Int. Symp. on Cadmium Telluride, Strasbourg 1971, Ed. P. Siffert and A. Cornet, Centre de Recherches Nucléaires (publishers), I.

[2] KyLE, N. R., ibid. IV.

[3] Triboulet, R., ibid. V.

[4] VANDEKERKOF, J., ibid. VIII.

[5] Mullin, J. B., MacEwan, W. R., Holliday, C. H. and WebB, A. E. V., J. Crystal Growth 13/14 (1972) 629. [6] DE Nobel, D., Philips Res. Repts 14 (1969) 361 and 430.

[7] SMITH, F. T. J., Met. Trans. 1 (1970) 617.

[8] Chern, S. S., Vydyanath, H. R. and Kroger, F. A., J. Solid State Chem. 14 (1975) 33.

[9] Selim, F. A., Swaminathan, V. and Kroger, F. A., Phys. Stat. Sol. (a) 29 (1975) 465

[10] Driscoll, C. M. H., Willoughby, A. F. W., Mullin, J. B. and Straughan, B. W., Proc. 4th Inter. Symp. on GaAs and Related Compounds, Deauville 1974, Institute of Physics, London (1975) p. 275.

[11] Mullin, J. B., Straughan, B. W., Driscoll, C. M. H. and Willoughiy, A. F. W., Proc. of the 2nd Int, Conf. on the Phys. of Compound Semiconductor Interfaces, Los Angeles (1975), CRC Critical Reviews in Solid State Sciences (1975) 441.

[12] Baker, T. W., George, J. D., Bellamy, B. A. and CauSER, R., Advances in X ray analysis 11 (1968) 359

[13] Driscoll, C. M. H. and Willoughby, A. F. W., Proc. of the Int. Conf. on Radiation Damage and Defects in Semiconductors, Reading 1972, Institute of Physics, London 1973, p. 377.

[14] Potts, H. R. and Pearson, G. L., J. Appl. Phys. 37 (1966) 2098.

[15] Kiseleva, K. V., Klevkov, U. V., Maximovsky, S. N., Medvedev, S. A. and Senturina, N. N., Proc. Int. Symp. on Cadmium Telluride, Strasbourg (1971), Ed. P. Siffert and A. Cornet, Centre de Recherches Nucléaires, XII.

[16] Thomassen, L., Mason, D. R., Rose, G. D., Sarace, J. C. and Schmitt, G. A., J. Electrochem. Soc. 110 (1963) 1127.

[17] Viapolin, A. A. and RUd', Yu. V., Inorg. Mater. 10 (1974) 470.
[18] Vook, F. L., Radiation Damage in Semiconductors, Vol. 3 (1964), Proc. 7th Int. Conf. on Phys. of Semiconductors, Paris 1964, Ed. P. Baruch, Academic Press, p. 51.

[19] Mullin, J. B., Straughan, B. W., Driscoll, C. M. H. and Willoughiy, A. F. W., J. Appl. Phys. 28 (1976) 2584.

[20] Meiling, G. S. and Leombruno, R., J. Crystal Growth 3, 4 (1968) 300 .

[21] Klausutis, N., Adamski, J. A., Collins, C. V., Hunt, M., LIPSON, H. and WeINER, J. R., J. Electron. Mat. 4 (1975) 625.

[22] Muluin, J. B., Crystal Growth and Characterisation, Proc. ISSCG 2 Spring School, Japan 1974, Ed. R. Ueda and Mullin, J. B. (North-Holland), 1975, p. 75.

[23] Mullin, J. B., Straughan, B. W. and Brickell, W. S., J. Phys. Chem. Solids 26 (1965) 782.

[24] Lunn, B. and Bettridge, V., Revue Phys. Appl. 12 (1977).

[25] Nygren, S. F., J. Crystal Growth 19 (1973) 21.

[26] Richards, J. L. and Crocker, A. J., J. Appl. Phys. 31 (1960) 611

[27] Hulme, K. F. and Mullin, J. B., Solid-State Electron. 5 (1962) 211

[28] Forsyth, P. J. E., Metcalfe, G. J., King, R. and ChalMERS, B., Nature 158 (1946) 875.

[29] HaAsen, P., Trans. AIME 209 (1957) 30 ; J. Metals 9 (1957) 30.

[30] Triboulet, R. and Marfaing, Y., J. Electrochem. Soc. 120 (1973) 1260.

[31] Ashen, D. J., Dean, P. J., Hurle, D. T. J., Mullin, J. B. and White, A. M., J. Phys. Chem. Solids 36 (1975) 1041.

[32] Panossian, J. R., Gippius, A. A. and Vavilov, V. S., Phys. Stat. Sol. 35 (1969) 1069.

[33] Taguchi, T., Shirafuji, J. and InUishi, Y., Phys. Stat. Sol. (b) 68 (1975) 727.

[34] Agrinskaya, N. V., Arkad'eva, E. N. and Matveev, O. A., Proc. Int. Symp. on Cadmium Telluride, Strasbourg 1971, Ed. P. Siffert and A. Cornet, Centre de Recherches Nucléaires (Publishers) IX. 